\title{
Assessment and decision making under the spotlight:
}

The roles of student, practice teacher, tutor

and university in four failed social work placements

\author{
Marguerita McGovern ${ }^{1}$
}

\begin{abstract}
In social work education failing placement is a seismic event. There are many complex reasons why placements fail; the student fails the placement, the placement fails the student, the practice teacher fails the student, the student fails themselves and the university fails or upholds all. With a failed placement the spotlight falls on the student, the practice teacher, tutor and the university. There are professional standards, reputations, academic policies and procedures at stake, notwithstanding the protection of the service user as the central concern. This article presents four failed Masters in Social Work placement assessments, two case examples from practice failures and two from portfolio failures. Analyses and reports are shared from initial difficulties and procedural organization, through to the forensics of final decision. Consideration is also given to current research and a 'what happened next' section is included.
\end{abstract}

Keywords: Failing placement; social work; difficulties; assessment; evaluation

Address for correspondence: Marguerita.mcgovern@nuigalway.ie

1.

Date of first (online) publication: 22nd January 2021

\section{Glossary of Terms:}

Practice Teacher/Fieldwork Supervisor/Field Educator/Practice Educator are all terms to denote the person responsible for assessing and evaluating the social work student on professional placement training.

Fieldwork Placement/Fieldwork Practicum/Placement Practice are all common terms for the period of time a social work student leaves their College/University and attends an agency for professional training

64 J. of Practice Teaching \& Learning 17(3), pp.64-81. @ w\& - b 


\section{Introduction}

The structure of this article considers the inter-connections between assessment and evaluation and its role in influencing event outcome. It is interesting to study why some students underperform on placement and to investigate the actual lived experiences of the student and practice teacher. The four case examples within this study are taken from a Masters in Social Work (MSW) course at an Irish university. In this university the MSW placement experience is organized by the Practice Learning Coordinator and is a full time 14weeks (500hrs) experience for each year of the MSW, in a variety of both statutory and voluntary professional social work settings. Each student is supervised on site by a professional social worker (Practice Teacher) with the addition of a personal off-site Tutor involved in two site based tri-partite placement meetings. In partnership with third level education, professional social work education in Ireland is regulated by the Irish health and social care professionals Council and Registrations board CORU (2010). Their assessment model for professional training is outlined under six domains; professional autonomy and accountability, interpersonal and professional relationships, effective communication, personal and professional development, provision of quality services and knowledge, understanding and skills. Formal supervision (one hour per week) for the student on placement oversaw case work, group work, theory to practice, legislation, human rights and reflective practice. Informal supervision (throughout the placement) includes information gathering, general discussion and communication within the team and agency. Fieldwork placement accounts for 50\% of the overall MSW course assessment (academic plus placement).

Practice teachers taking a student, are offered by the university, three in-service training days. Additionally, the university offers a one year Postgraduate Diploma in Social Work Practice Teaching, Supervision and Management. Students pre-placement training is taught over twelve weeks in two hourly sessions by the Practice Learning Coordinator and MSW staff. Attendance is mandatory. The basic aims are to familiarizing students with general assessment details, explore placement expectations and build a sense of togetherness.

At the end of placement each student produces a portfolio as evidence of their learning (7,000 words in year one and 8,000 words in year two). Practice teachers submit their assessment to the university as a Performance

65 J. of Practice Teaching \& Learning 17(3), pp.64-81. @ wE-b 
Evaluation Report (PER) guidelines of which are directed by the course outline and the Irish social work registration board CORU (2012).

Based on the Performance Evaluation Report (PER) and Portfolio mark, students are graded Pass/Fail on their PER and given a percentage mark for their Portfolio. Normal university procedures are applied in relation to review and appeal of marks. Supporting the assessment process is the Practice Assessment Panel (PAP) meeting twice a year and reviewing a random sample of placements both passed and failed. This panel is constituted for the purposes of quality assurance of placements. It ensures the standards and procedures in the assessment are fair, consistent and appropriate and makes recommendations to the External Examiner. The membership of PAP consists of MSW staff and senior community based social work practitioners. With failed placements the student is required to submit to the PAP a 'Report of Learning'. A student failing the PER may be asked to undertake a further placement in an alternative service. Normally students are permitted one opportunity to repeat a placement. In the case of a failed portfolio the student is asked to re-submit with direct relevance to the remarks made by the marker and the Practice Assessment Panel.

Tutors for MSW students are senior social work practitioners and social work academic staff. Their role is one of supporter/mentor and not placement assessor. Training is offered as two half day sessions per year, attendance is mandatory.

\section{Aims and objectives}

The aims and objectives of this study were to consider four social work placement assessments with a fail grade. It was also important to present the views of practice teachers and students in how they interpreted the parameters of the assessment tool and their reasoning behind difficult decisions. Additionally quality control and support systems of the university were to be considered, including the role of the tutor and the opinion of the Practice Learning Coordinator. It was also intended to explore the future direction taken by the students following the fail experience.

66 J. of Practice Teaching \& Learning 17(3), pp.64-81. @ w\& b 


\section{Method}

For this research article four failed placement cases were randomly selected for review by the author from placements conducted over the period 2012-2019. The roles of all stakeholders; student, practice teacher, tutor and university were identified and particular consideration was given to selecting the areas in which the students were deemed to have failed in the placement assessment. It was of interest to explore the meaning and interpretation of that experience and to critically observe, reflect and evaluate the process. The inclusion of 'Author's Note' after each section was deemed important to give extra information and promote dialogue and understanding of the event. The Practice Learning Coordinator, in the university selected, not only organizes, supports and monitors placements but teaches various modules on the MSW course and therefore is particularly familiar with all of the students, practice teachers and tutors.

For this study identifying names, service settings and geographical locations were changed in line with (European) General Data Privacy Regulations (GDPR). It is noted that ethical consideration and individual permission for use of data is given each year by all registered MSW students, tutors and practice teachers in order to support ongoing social work training and research. Further informed consent was sought and granted by those referenced in the selected four case studies.

\section{The importance of assessment and evaluation}

The requirement of an assessment tool is to be fair, accurate, efficient, a good fit for the tasks in hand, resulting in elevated learning (Killick and Taylor, 2020; McGovern, 2016; Barron, 2004). Critically, it should be achievable, reasonable and represent a growth of knowledge across a period of training. For students, understanding clear assessment criteria helps to bring focus on social work delivery models, gaining feedback on practice, building emotional resilience and reviewing approaches to relationships with individuals, families and communities (Parker, 2017; Eno and Kerr, 2013). It is important to understand the function of good assessment on placement in building a supportive culture regardless of time constraints, work demands, little self-care and inadequate supervision (Grant and Kinman, 2014; Govaerts et al., 2006). In particular, Lefrevre's (2005)

67 J. of Practice Teaching \& Learning 17(3), pp.64-81. @ wE-b 
research demonstrates that students linked their perceived level of the fairness of their placement assessment and their ability to learn, with their relationship with their practice teacher. Furthermore, it is encouraging that those students who understood good professional assessment excelled in future professional careers (Taylor et al., 2018). Assessment tools work if practice teachers have confidence, wisdom and experience to ascertain the quality of the student output over a period of time. That good assessment acts on two levels, one as gatekeeper, upholding the ethics and standards of the profession and the other regarding decision making and risk (Elpers and Fitzgerald, 2013; Miller and Koerin, 2001; Cole and Lewis, 1993). This underpins the purpose for practice teachers to be 'open, collaborative, supportive and nurturing' (Brodie \& Williams, 2013; Doel et al.1996) and that their feedback will be timely, constructive and honest in how it is given and received (Brown, Peterson and Yao, 2016; Bogo, 2006). At times, assessment and evaluation tools do not work. They can be seen as biased, subjective and uncertain, focusing on gender (Vakalahi et al., 2014; Furness, 2012; Hussein et al., 2008; Messinger, 2004), race (Brown, 2019; Hollingsworth et al., 2018; Williams, 2017; Masocha, 2015; Tedam, 2014; Fairlough et al., 2014; Thomas et al., 2012) and cultural world view (Lin and Appleton, 2018). The growing trend towards litigation and appeals can further question and destabilise assessment criteria and techniques, making practice teachers wary and universities cautious (Garthwait, 2005 p. 44).

\section{Findings}

The finding from this small study support observations from the literature that the failing situation can be equally traumatic for the student, practice teacher, tutor and the university (Finch, 2017; McGovern, 2016; Beddoe and Davys, 2016; Finch, Schaub and Dalrymple, 2014; Barlow and Hall, 2007; Baum, 2007; Burgess et al.,1998b). The four cases outlined consider both the experiential (doing) part of the placement and the academic (writing) part of the placement illustrating the significance of both in the journey towards professional practice.

68 J. of Practice Teaching \& Learning 17(3), pp.64-81. @ w\& b 


\section{Case 1}

MSW Year 1 student in a statutory Children in Care team failing their placement experience. The student had a registered disability. Ten weeks out of a fourteen week placement were completed. Opportunities on placement included; individual casework, family casework, groupwork, community and youth work. Introduction to court work and related agency visits were organized and exposure to team meetings, report writing and duty cover were also available. The student's main learning needs included; understanding the role of the social worker with regard to children in care, improvement of interpersonal and communication skills and the ability to link theory to practice.

The practice teacher's report (PER) stated the student was pleasant, friendly and outgoing but the placement was a challenge in terms of length to reach the required professional standards. The student showed little initiative and needed excessive guidance and support. Examples of poor professional practice were cited as; the student interrupting colleagues and clients without waiting for full explanations or direction; evidence of difficulties around ethical, legal and personal boundaries; the student being reminded a number of times on the unacceptability of sending correspondence from personal email accounts to clients. Furthermore there was also a breech of case confidentiality. The practice teacher emphasized that when examples of poor practice were discussed with the student there was negligible realization on lack of skills and at times the student in supervision became upset and emotional. By the end of the placement the practice teacher remained concerned that the student was not engaging enough to demonstrate the learning offered or standards to be achieved.

With regard to the Student's Report to the Practice Assessment Panel (PAP) the student acknowledged particular personal confusion and feelings of trauma and drama. They admitted their initial anger was directed towards the practice teacher but actually on reflection felt most anger towards themselves. They felt they had 'let themselves down'.

The Practice Assessment Panel (PAP) upheld the fail grade.

\section{What happened next?}

The student was very emotional over the Fail situation. Support was offered by the personal Tutor and the Practice Learning Coordinator in the form of a meeting before and after the PAP gave their decision and after the External Examiner upheld the Fail grade. An additional placement (as

69 J. of Practice Teaching \& Learning 17(3), pp.64-81. @ wE-b 
per course outlines) was offered with no extra university fee implications. The additional placement was passed. The student completed and passed the second year of the MSW and is currently employed as a social worker.

\section{Author's Note}

This student had a registered disability. No parties (including the student) involved in the placement suggested there were any difficulties around mobility or physical attributes contributing to the fail. The student and practice teacher had met prior to placement to discuss all relevant issues and in addition a discussion had taken place between the practice teacher and the Agency's line manager (Social Work Team Leader). It was important in this case to make sure that all communication lines were open and all stakeholders in this placement felt informed and supported.

Following on from the Fail grade the student engaged with the university's Counselling Services and the university's Disability Services for personal support. In their 1998 research Burgess et al. (1998) discuss how some students who fail, exhibit anger, frustration, shock and disappointment, their communication skills becoming disrupted, their progress cumbersome and supervision laboured. In this case the initial reaction of the Practice Learning Coordinator was to look for contributing factors to the fail with regard to the disability. Were there restrictive practices around physical movement? Had any psychological pressures been ignored? This was not the case.

\section{Case 2}

MSW Year 1 student in a statutory (HSE/TUSLA) Fostering team failing their placement experience. The full fourteen weeks of placement were completed. The practice teacher was highly experienced and had taken students previously without any difficulties. Whereas this student had completed and passed all academic first year subjects the teaching staff expressed concerns regarding the student's lack of professionalism in class. Opportunities on placement included; seven cases involving advising and informing couples on fostering. The practice teacher would further supervise the student on a full fostering assessment. Attendance was required at fostering placement meetings, team meetings and case conferences, court attendance and the supervision of an access case would additionally contribute to the student's learning.

70 J. of Practice Teaching \& Learning 17(3), pp.64-81. @ w\&bb 
The student's main learning needs were identified as follows; understanding the role of the professional fostering social worker, familiarity with the fostering process and its legal basis and the identification of the student's own strengths and weaknesses.

Evidence for the fail grade appears in an extract from the submitted Performance Evaluation Report (PER) written by the Practice Teacher.

There was some evidence of empathy and standardization, as the practice teacher, I could see the ability of the student who had extensive life and work experience. However, there was no consistency in self awareness or self reflection throughout the placement even after numerous discussions on these topics during supervision.

Examples within the PER suggested this student appeared to have an exaggerated view of their own personal and professional strengths and weaknesses. The report stated that any form of criticism of the student was greeted by the student saying 'That's a surprise!'.

Issues regarding non-involvement, non-engagement, being distracted by personal commitments and the overall need for constant guidance and direction were noted. Furthermore the PER suggested the student showed no confidence when interviewing, lacked sufficient information and at times presented faulty data. Listening skills were lacking and at one point during a family meeting the student appeared to 'doze off'.

There was an important addendum to this practice teacher's evaluation report which is worth considering. The practice teacher wrote

I mentioned (three weeks before the end of placement) to the student that I intended on giving a Pass grade for the placement. This I clarified by saying that the grade was 'just about a pass' but with a strong warning the student would need to improve greatly in their second placement. However, the two final weeks were the decisive factor for me in giving the Fail, when the student cancelled the final supervision meeting and again took time off from placement. In my view this student had little insight into the inconvenience of cancelling the joint final meeting. Overall, it took me a long time to actually grasp what the actual issues were in relation to this student. I am sorry I was not able to figure this out sooner.

The student submitted their own report to the Practice Assessment Panel (PAP) disputing what they felt were unfounded allegations regarding non-commitment to learning and lack of communication skills. With regard to their 'dozing off' episode the student wrote

71 J. of Practice Teaching \& Learning 17(3), pp.64-81. @ wE-b 
The Practice Teacher also referred to me closing my eyes on occasions and assumes that I was either tired or bored by the procedures taking place. I was not asked about this at the time. However, if I had been, I would have been able to clarify this matter. I underwent laser surgery recently and am sometimes affected by bright lights, which result in my having to close my eyes for a few seconds at a time when they become dry and sore due to sunlight or bright lights. The accusation that I appeared to doze off is unfair and harsh.

In general the student felt the failures regarding communication and poor assessment were more evident in the Practice Teacher and that there were inconsistencies and contradictions in the PER and confusion whether the placement was passed or failed.

\section{What happened next?}

The Fail grade was upheld by the Practice Assessment Panel and the External Examiner both stating that the evidence across the assessed CORU domains cited by the Practice Teacher was not sufficient to pass the student. The student considered taking the situation further to the university's Appeals Board but in the end accepted the Fail grade and went on to an additional placement (in a different geographical area at the student's request). The additional placement was passed as was MSW year 2. It would appear the individual in this case study is not currently employed in social work.

\section{Author's Note}

Should the Practice Learning Coordinator have offered more structured and timely direction to both parties and been involved much earlier in this placement? There is the possibility that earlier intervention with additional supports and direction may have identified difficulties for both parties sooner given that staff members had previously expressed concerns regarding this student. The tutor's role was not dominant except to partake in the tri-partite meetings and this could have been further explored. Were there issues here reflecting power and/or personality difficulties on both sides? It is difficult to judge without evidence. In the research of Parker (2010) the suggestion is made that disruptive, marginal and failing placements can have an element of power issues and imbalances. Overall, what is seen in this Case 2 is a collection of issues not properly or timely investigated.

72 J. of Practice Teaching \& Learning 17(3), pp.64-81. @ w\&bb 


\section{Case 3}

This is a case example of an MSW Year 1 student on placement in a statutory Child Protection team passing their placement experience (PER) but failing their Portfolio. The placement continued for the full fourteen weeks and the usual arrangements for formal and informal supervision were followed. Opportunities on placement included; five cases (focusing on individual and family casework) plus attendance at case and family welfare conferences. Child protection joint screening interviews and various administrative duties were to be covered with the opportunity to write a court report and be involved in groupwork. The learning needs of the student were to acquire the skills and knowledge in working with children and families who have/are experiencing domestic violence and to overall improve interviewing and communication skill techniques.

The Practice Teacher in the PER rated this placement as being 'highly successful'. The student was deemed to be exceptionally professional and competent with excellent professional integrity and a good ability to forge positive working relationships with children and families.

Difficulties arose for the student in being able to evidence their learning within the Portfolio.

(Portfolios markers are Tutors chosen at random and not the student's own personal Tutor). The remarks from the marker of this Portfolio concentrated on the lack of critical analysis as evidenced specifically in the Portfolio Law, Reflective Practice and Human Rights sections. In particular the marker pointed out 'a lack of evidence prevailed on how the student understood reflective practice and the impact on self'. More in depth discussion and the use of stronger examples from placement were requested. With regard to the legal underpinning of this placement the marker found some useful descriptions of the relevant law and policy but the student failed to demonstrate a more critical understanding of the relevance of the law. Overall it was felt the Portfolio was further hampered by simple spelling and grammatical errors and lacked a 'basic final edit'.

The PAP upheld the failed Portfolio grade.

\section{Author's note}

It was clear from the student's conclusion and also the Practice Teacher's report (PER), that the student responded well to the teaching and learning available. Many students pass the 'practice' but find it hard to articulate in words what they have learned. This is interesting as on both undergraduate

73 J. of Practice Teaching \& Learning 17(3), pp.64-81. @ wE-b 
and postgraduate courses students will have written and passed countless academic essays before the placement module occurs. The language used in writing between course and placement can be interchangeable but on placement it has a more applied focus.

What happened next?

The student accepted the Portfolio Fail grade and was given the correction remarks. The student resubmitted the Portfolio within three weeks. The resubmitted Portfolio was passed with all comments and recommendations taken into account. The student graduated the following year with both final PER and Portfolio passed on initial hand-up.

\section{Case 4}

This concerns a second year MSW failed Portfolio case with the full placement being completed over the required period of 14 weeks. This was a 'split' placement between Child and Adolescent Mental Health Services and Adult Mental Health Services. The Practice Teachers had previously taken students and also had had the experience of failing students.

There was a wide variety of learning opportunities on this placement. The student carried five individual and five family cases. Participation in court work and the co-facilitation of a weekly communications and anxiety management group were available. Attendance was expected at family conferences, review meetings, child care planning meetings along with involvement in inter- agency meetings between Mental Health services and the statutory Child and Family Agency (TUSLA). Additional short training was offered on Domestic violence and mental health legislation.

The student's learning needs concentrated on being more confident in interactions with service users and improving their counselling skills. Understanding the role of the mental health social workers in both agencies was also important.

The Practice Teachers from both agencies came together to write the PER. The overall summery suggested that the student demonstrated an excellent level of practical competency, showing good leadership skills by communicating good decision making and articulating difficult professional judgments. A pass grade was recommended for the placement experience.

On marking the student's Portfolio the following comments were noted

74 J. of Practice Teaching \& Learning 17(3), pp.64-81. @ w\&bb 
With regard to the presentation and structure, the layout was good but the work had many repeated grammatical and typing errors, for example, 'I had being supporting with a young expectant woman .... It was being very clear that there where properties available .... and my client's needs where the same as ....

A final editing process was suggested. With regard to the student's overall learning needs the marker commented that they could have been better tailored to the agencies' opportunities for learning.

What happened next?

The student accepted the comments and Fail grade on the Portfolio and went on to resubmit. The resubmitted Portfolio was passed as the student's writing ability improved and less casual mistakes were noted in the rewrite.

Unfortunately although the student passed both placements they did not complete the SW course.

Author's Note:

Deciding on specific learning needs can shape the learning experience for the student going into placement. Too narrow and the learning experience is stunted, too broad and the experience can be overwhelming. Many students decide on their learning needs by identifying skills, organisational knowledge and by understanding the role of the social worker. Writing the evidence of these in a portfolio for some students can be challenging if they have not been explicit in qualifying what they wanted to learn and if any earlier difficulties regarding academic assessments have not been sign posted.

\section{The role of the tutors in cases 1 to 4}

Tutors need to share their broader understanding in a planned way with students, enabling them to make informed decisions about the course and their abilities to maximise learning across its duration. (Watson \&West, 2003)

In all of the Fail cases brought before the PAP and the External Examiner, tutors were asked for their report accompanied by copies of the Tri-partite forms. Their role is set out as mentors and advisors to the students acknowledging that the university's practice is for the student to have the

75 J. of Practice Teaching \& Learning 17(3), pp.64-81. @ wE-b 
same tutor in the case of failed or additional placements. However, in Case 3 the student requested a different tutor for their additional placement citing lack of confidence in being adequately supported. In cases 1,2 , and 4 the student's acknowledged their tutor as mentor, supporter and advisor. In considering the failed placements, Tutors' reports were most useful when they set out specific timelines and identified concerns. This was evident in one Tutor's report which began 'Concerns were raised regarding ....' or 'As I understand it ..... Another Tutor offered the perspective 'Here is a timeline of difficulties from my understanding as the Tutor ....' followed by a chronological table.

\section{Limitations and future exploration}

The data from this small scale research study utilizes four failed placements, over a period of seven years, from a university MSW course. General conversations with Practice Learning Coordinators in other Irish universities would suggest that these assessment failures are typical samples although there is no current Irish research to support these views. It is suggested that future research with greater numbers of failed placements could look for patterns within failed placements with additional concentration on a more forensic examination of the assessment tool, it's application and 'fit for purpose' use. There is also consideration that a comparison group of students who have passed their placement assessment could be used to compare and contrast the similarities and differences in approach to certain assessed domains.

\section{Discussion and conclusion}

The system of assessment has to be fair, robust, standardized and fit for purpose (Kenta et al., 2018; Murray and McGovern, 2015; Cowburn, et al. 2000; Kemshall, 1993). Practice teachers are required to assess students and by default be gatekeepers of the profession. With regard to the placement examples presented, the aspect of timing is most interesting. The majority of students went to the end of placement before a fail was identified. Was this lack of decision making by the practice teacher,

76 J. of Practice Teaching \& Learning 17(3), pp.64-81. @ wE-b 
non-intervention by the tutor, unclear guidelines by the university or the need to give the student every possible opportunity to meet the assessment criteria within the time frame? Significantly in the PERs, particularly Cases 1 and 2 reflect the student's lack of consistency, inability to listen, learn or take direction. In these cases the Practice Teachers adopted a more task orientated approach in order to find a way to quantify the amount of learning taking place and use this approach as evidence within their PERS. Comparing Cases 3 and 4, the students' skills in practice were excellent but their problems became evident in being able to write and reflect on those experiences. With particular reference to the Portfolio, some students found writing the evidence of their placement experiences challenging. At times there were difficulties with language or sentence construction, an inability to find or reflect adequately on what and how the learning had taken place or why an intervention was necessary. Social work students execute college essays and assignments in a systematic regulated way, collecting resources and critically assessing arguments. On placement, report writing for agency work may be strictly on-line, follow a regimented pattern and require the author to be clear, concise and confident. The student therefore now understands two approaches to writing but the Portfolio requires a third consideration, that of being able to transfer the assessment of contextual experience into words, while being additionally able to consider assessment domains.

An interesting debate arises on timing and clarity (Cases 1 and 2). Was the practice teacher fair or unfair in telling the student they had passed but to renege on this a short time later (Case 2)? Equal confusion was evident in Case 1 where there was expressed worry by the student in not understanding the reason for failing. If pre-placement training in the assessment and evaluation pathways are clear both student and practice teacher should have no difficulty understanding their position. At each point in the tri-partite meetings clear understanding of how the student is developing should be discussed and evidence of any difficulties shared.

The teaching of quantifiable systems within placement can be straightforward but in the event of failing their student, each of the practice teachers, reflected on their emotions. Feelings of sadness, upset and unease predominated but there were also feelings of satisfaction in being able to assess the student fairly and with confidence. The practice teachers agreed they had 'grown with the experience' and it was encouraging that overall they did not feel deterred from taking other students on placement in the future.

77 J. of Practice Teaching \& Learning 17(3), pp.64-81. @ w\&b 
In conclusion this limited study has afforded the opportunity to consider a number of points in relation to fail grades on placement. This begins with the selection of the best candidates for training. With present undergraduate and postgraduate social work courses many universities are now forgoing face to face interviews in lieu of screen interviews and direct entry. This may be inevitable with large course intakes but for postgraduate training and smaller intakes, the ability to sit in proximity to the interviewee and assess all aspects of their career choice during interview is important. With placement assessment accounting for $50 \%$ of social work courses, pre-placement training for practice teachers, students and tutors is vital. If assessment is to be fair, balanced, constructive, achievable and understood, all parties need to appreciate how to evidence the basic procedures and policies.

All personnel involved in placement aim for success and successful relationships. Indeed the majority of students pass their placements in triumph. The future will hold many challenges for new social work graduates; tightening resources, accountability and confidentiality in a digital age, inter-generational and multiple problems for service users with services becoming more acute and intractable. Assessment of students and the fair grading of placement is crucially important, it cannot be 'good enough' or 'just about passable' because professional social work requires higher standards.

\section{References}

Barron, C. (2004) 'Do We Need a Second Opinion Here?' Journal of Practice Teaching, 5, 2, 22-38

Barlow, C. and Hall, B.L. (2007) 'What about feelings?': A study of emotion and tension in social work field education. Social Work Education, 26, 4, 399-413

Beddoe, L. and Davys, A. (2016) Challenges in Professional Supervision. London. Jessica Kingsley

Bogo, M. (2018) Social work practice: Integrating concepts, processes, and skills. New York: Columbia University Press

Bogo, M. (2006) Field Instruction in Social Work: A Review of the Research Literature. Clinical Supervisor, 24, 1/2, 163-93

Brodie, I. and Williams, V. (2013)'Lifting the Lid: Perspectives on and Activity within Student Supervision. Social Work Education, 32, 4, 506-522

78 J. of Practice Teaching \& Learning 17(3), pp.64-81. @ w\&bb 
Brown, G.T.L. and Peterson, E.R. and Yao, E.S. (2016) Student conceptions of feedback: Impact of self-regulation, self-efficacy and academic achievement. British Journal Educational Psychology, 86, 4, 606-629

Brown, S.L., Johnson, A. and Millar, S.E. (2019) Racial Microaggressions and black social work students: a call to social work educators for proactive models informed by social justice. Social Work Education, 38, 5, 618-630

Burgess, R., Philips, R. and Skinner, K. (1998) Practice placement that go wrong. Journal of Practice Teaching, 1, 2, 48-64

Cole, B.S. and Lewis, R.G. (1993) Gatekeeping through termination of unsuitable social work students: legal issues and guidelines. Journal of Social Work Education, 29, 2, 150-159

CORU Health and Social Care Professionals Council, 2010) Accessed 10/9/2020 at http://www.coru.ie/en/about_us/social_workers_registration_board

CORU health and social Care Professionals Council (2012) Standards of Proficiency for Social Workers. Accessed 10/9/2020. https://coru.ie/files-education/swrbprofession-specific-criteria-for-education-and-training-programmes.pdf

Doel, M., Shardlow, S., Sawdon, C. and Sawdon, D. (1996) Teaching Social Work Practice. Hampshire. Ashgate Publishing

Elpers, C. and Fitzgerald, E.A. (2013) Issues and Challenges in Gatekeeping: A Framework for Implementation. Social Work Education, 23, 3, 286-300

Eno, S and Kerr, J. (2013) 'That was awful! I'm not ready yet, am I?' Is there such a thing as a good fail? Journal of Practice Teaching and Learning. Special edition, $11,3,135-48$

Fairlough, A., Bernard, C. and Ahmet, A. (2014) Black Social Work students. Experience of Practice Learning. Journal of Social Work, 14, 6, 605-624

Finch, J. (2017) Supporting Struggling Students on Placement: A practical guide. Policy Press

Finch, J., Schaub, J. and Dalrymple, R. (2014) Projective Identification and the Fear of Failing: Making Sense of Practice Educators Experiences of Failing Social Work Students in Practice Learning. Journal of Social Work. Practice, 28, 2, 139-154

Furness, S. (2012) Gender at Work: Characteristics of 'failing' social work students. British Journal of Social Work, 42, 3, 480-499

Garthwait, C.L. (2005) The Social Work Practicum. (3rd ed.) Boston: Pearson

Govaerts, M., Van der Vleuten, C., Schuwirth, T. and Muijtjens, A. (2006) Broadening perspectives on clinical performance assessment: Rethinking the nature of in-training assessment. Advances in Health Science Education, 12, 239-26

Grant, L. and Kinman, G. (Eds.) (2014) Developing Resilience for Social Work

79 J. of Practice Teaching \& Learning 17(3), pp.64-81. @ wE-b 
Practice. London: Palgrave Macmillan Education

Hollingsworth, L.D., Patton, D.U., Allen, P.C. and Johnson, K.E. (2018) Racial microaggressions in social work education: Black students' encounters in a predominantly White institution. Journal of Ethnic \& Cultural Diversity in Social Work, 27, 1, 95-105

Hussein, S., Moriarty, J., Manthorpe, J. and Huxley, P. (2008) Diversity and progression among students starting social work qualifying programmes in England between 1995-1998: a quantitative study. British Journal of Social Work, 38, 8, 1588-609

Kemshall, H. (1993) Assessing competence: scientific process or subjective inference? Do we really see it?' Social Work Education, 12, 1, 36-45

Kenta, A., Bogo, M., Good, B. and Power, R. (2018) Teaching Note-Social Work Serial: Using Video-Recorded Simulated Client Sessions to Teach Social Work Practice. Journal of Social Work Education, 54, 2, 397-404

Killick, C. and Taylor, B. (2020) Assessment, Risk and Decisional Making in Social Work: An Introduction. Transforming Social Work Practice Series. London: Sage

Lefevre, M. (2005) Facilitating practice learning and assessment: the influence of relationship. Social Work Education, 24, 5, 827-840

Lin, J. and Appleton, C. (2018) Working with Chinese Social Work Students: Useful concepts and support strategies. Advances in Social Work and Welfare Education, 20, 2, 151-157

Furness, F. (2012) Gender at Work. Characteristics of Failing Students. British Journal of Social Work, 42, 3, 480-499

Masocha, S. (2015) Reframing black social work students' experiences of teaching and learning. Social Work Education, 34, 6, 636-649

Matthew, L.I. and Lough, B.J. (2017) Challenges social work students encounter in internation field placement and recommendations for responsible management. Journal of Social Work Education, 53, 1, 8-36

Messinger, L.(2004) Out in the Field: Gay and Lesbian Social Work Students experiences in Field placement. Journal of Social Work Education, 40, 2, 187-204

McGovern, M. (2018). Social work placement: New approaches. New thinking. Assessment, Creative Supervision, Feedback. Book 2. Galway: NUI Galway (accessed 1/4/2020) https://aran.library.nuigalway.ie/handle/10379/10018

McGovern, M. (2016) Social work placement: New approaches. New thinking. Failing Forward. Book 5. Galway: NUI Galway (accessed 3/4/2020) https://aran.library. nuigalway.ie/handle/10379/10022

Miller, J. and Koerin, B.B. (2001) Gatekeeping in the Practicum: what field instructors need to know. Clinical Supervision, 20, 2, 1-18

Murray, R. and McGovern, M. (2015) Two sides of the one coin: Assessment of

80 J. of Practice Teaching \& Learning 17(3), pp.64-81. (C) w\&b 
students who have previously failed a placement and the role of the practice teacher. The Journal of Practice Teaching and Learning, 13, 2-3, 73-87

Parker, J. (2017) Social Work Practice: Assessment, planning, intervention. . London: Sage/Learning Matters

Poletti, A. and Anka, A. (2013) 'They Thought I wasn't good enough for social Work practice.' Journal of Practice Teaching and Learning, 11, 3, 17-35

Royce, D. (2000) The ethics of gatekeeping. in P. Gibbs and E.H. Blakely (eds. Gatekeeping in BSW Programs Ne York:Columbia University Press

Taylor, B., Killick, C., Bertotti, T., Enosh, G., Gautschi, J., Hietamäki, J., Sicora, A. and Whittaker, A. (2018) European Social Work Research Association SIG to Study Decisions, Assessment, and Risk. Journal of Evidence-Informed Social Work, 15, 1, 82-94

Tedam, P. (2014) When failing doesn't matter: A narrative inquiry into the social work practice learning experiences of Black African Students in England'. International Journal of Higher Education, 3, 1, 136-145

Thomas, G., Howe, K. and Keen, S. (2012) Supporting Black and minority ethnic students in practice learning. The Journal of Practice Teaching and Learning, 10, 3, 37-54

Vakalahi, H.F., Sermon, M., Richardson, A., Dillard, V. and Moncrief, A. (2014) 'Do you see me?' The complex experiences of women of color MSW students. Intercultural Education, 25, 5, 418-427

Williams, N. (2017) Recognising the Needs of Black social work students. Social Work with Groups, 40, 1/2, 124-128

81 J. of Practice Teaching \& Learning 17(3), pp.64-81. @ wE-b 